\title{
Toque educativo relacional
}

Adolfo Araujo Romagoza

\section{Palabras claves:}

Epistemología relacional, toque relacional de Simmerhills, prácticas democráticas, educación deliberativa

\section{En términos}

\section{epistemológicos, también}

es posible que la escuela,

\section{en su afán de trasmitir}

\section{conocimientos entre un}

\section{maestro y su alumno,}

\section{haya olvidado que existe}

\section{una relación entre los}

mismos de lo cual puede

resultar un fracaso o

un éxito y que, por lo

tanto, esta relación

resulta muy importante

\section{para el mantenimiento}

\section{de aprendizajes}

\section{significativos $\mathbf{y}$,}

de largo plazo.

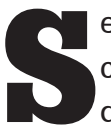

e trata de aproximarse conceptualmente a un esfuerzo de convertir la escuela tradicional en una escuela que fortaleza la democracia, que se fundamente en la libertad y en el afecto, en aras de formar ciudadanos que busquen el bien común.

El mapa conceptual mostrado en el anexo 1, puede constituir una aproximación de la realidad en algunos centros educativos que operan con moldes y modelos tradicionales, en los que claramente se puede percibir la preeminencia del autoritarismo excedido, el cual se caracteriza por los componentes siguientes:

\section{TEMOR O MIEDO}

Se reprimen iniciativas democráticas, no existen evidencias visibles de prácticas quefavorezcan la democracia, no se cuenta con alumnos con voz ni voto, ni con originalidades, deseos e intereses de los mismos.

La organización es vertical, unilateral, de arriba hacia abajo, con un alto poder concentrado en cúpulas sean estas de dirección escolar o de asociaciones de padres de familia.
Un poder concentrado y excesivo trastoca la vida en democracia, se toman decisiones inconsultas en las áreas administrativas, se desvían fondos hacia intereses no educativos, se adquieren bienes o productos que no contribuyen a la mejora de la calidad educativa $y$, en lo sustantivo, el poder centralizado en lo académico hace que se valoren aspectos de forma tales como el uniforme, los zapatos, la trasmisión de información, lo intelectual, lo individual, la comparación entre diferentes, la sumisión, el aspecto físico en general, la burla por creencias culturales, el irrespeto, etc., etc

\section{NO NATURAL}

Hay algunos casos en los cuales se obliga a los alumnos a obedecer patrones antinaturales tales como modos, comidas, aulas no adecuadas, el tener que estudiar contenidos academicistas alejados de nuestra realidad y sin utilidad, sin libertad de opinar, sin poder ejercitar la responsabilidad, ni la posibilidad de amar la vida (biofilia) y apreciar el bien común, la dignidad y el libre desarrollo. Todo es negro o gris. Se hace énfasis en la tormenta y no se valora, ni se ve, el arcoiris. 


\section{Un buen proyecto,} según el actor

citado, se indica (es

visible) porque lo

público es político,

\section{la deliberación es}

cotidiana, se aprende

para la argumentación

y también para poder

aceptar explicaciones.

Es informada y respeta

los derechos humanos,

valora la reciprocidad

y se deja con tiempo

suficiente para que las

\section{deliberaciones fluyan}

libremente.

\section{MACHISMO}

"Los hombres no Iloran". Lo afectivo no cuenta, se considera debilidad dejar salir las emociones; estas deben ocultarse, reprimirse y eliminarse. En efecto, la escuela no debe ser un lugar en el que la felicidad predomine, debe ser seria, rigorista ('la letra con sangre entra'), inflexible ('yo tengo la razón, tú eres ignorante'), la alegría no ayuda, es mejor el silencio sepulcral, el orden, la disciplina estricta, el trabajo académico por obligación ('te castigo dejándote una investigación para mañana') y no por convicción.

La comparación entre alumnos ('Pedrito es mejor que Toñito'), que hace desaparecer las relaciones amigables en aras de valorar la competitividad individualista e insana. Se trata, consciente o inconscientemente, de desdibujar la identidad, la dignidad y la personalidad para dejar paso a lo estándar, lo uniforme, el mismo paso, el mismo ritmo y lo idéntico.

\section{MECÁNICA}

La educación tradicional prioriza lo intelectual, la no discusión de las ideas; es sin crítica y, en su afán de trasmitir contenidos, olvida valores; es constrictiva, reduccionista, asistemática, confusa, irrelevante, repetitiva, cansada, aburrida y, sobre todo, mecánica. Para esta escuela sólo cuenta el problema bien estructurado, hay una sola respuesta y un solo modo de llegar a ella. La respuesta es incuestionable y no se verifica ni se valida, y se le da por cierta e irrebatible. Ante esta situación, se presenta en seguida una nueva visión posible y concreta: Quién eres es más importante que lo que sabes o tienes.

\section{LA TEORÍA}

RELACIONAL

Es posible que la escuela tradicional esté basada en la ciencia tradicional, la cual siempre funcionó con el sentido del orden, la verdad incuestionable, la certidumbre matemática, la racionalidad $y$, por tanto, la escuela programada; el mundo lineal, estable, sin ruido ni indefiniciones.
Colom (2002) dice: “La innovación, el movimiento y la complejidad son los grandes enemigos científicos de las ciencias humano-sociales".

En términos epistemológicos, también es posible que la escuela, en su afán de trasmitir conocimientos entre un maestro y su alumno, haya olvidado que existe una relación entre los mismos, de lo cual puede

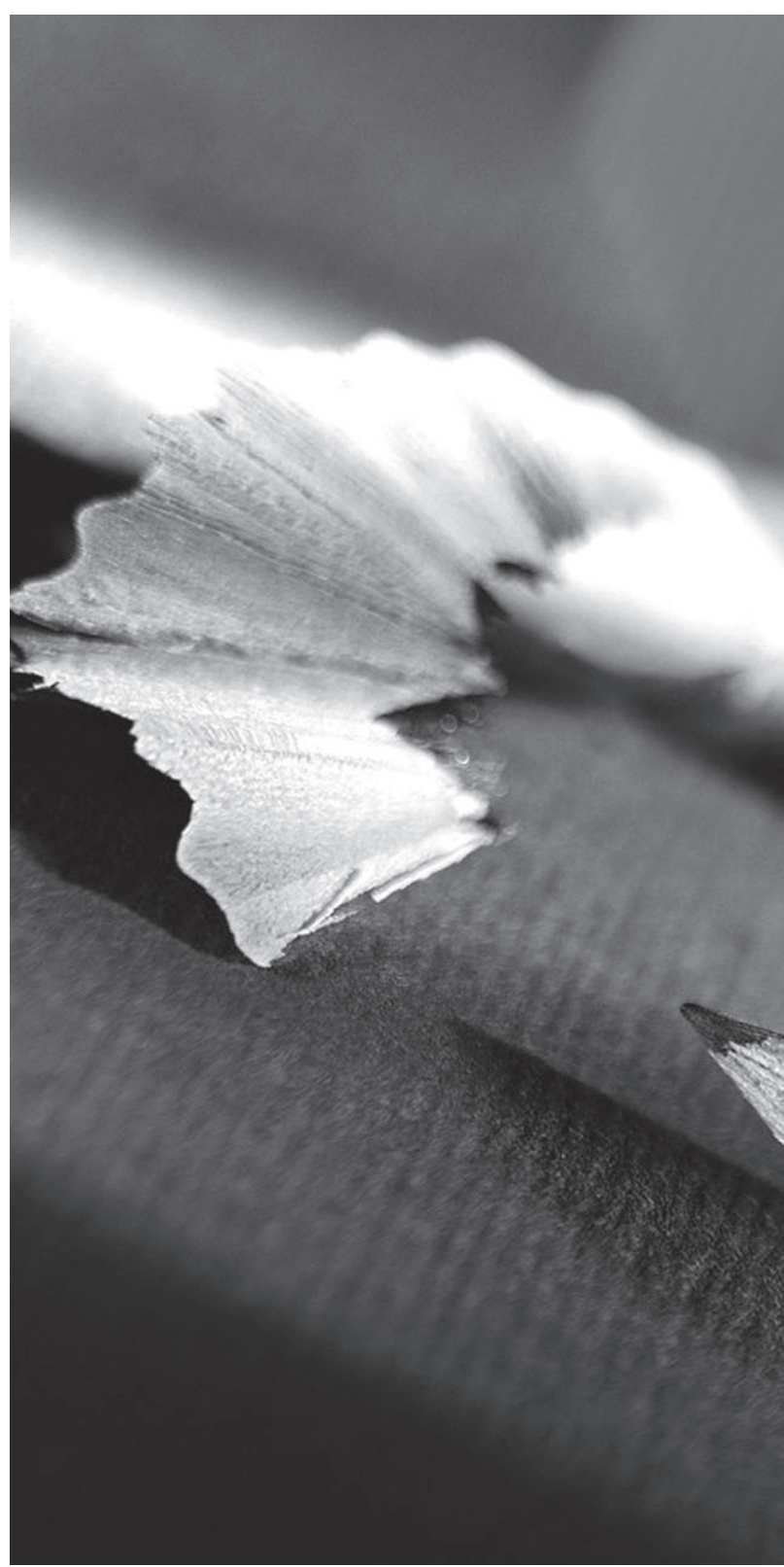


resultar un fracaso o un éxito, y que, por lo tanto, esta relación resulta muy importante para el mantenimiento de aprendizajes significativos y de largo plazo.

La identidad relacional es una imagen que la persona establece de sí misma, en relación con otras personas que la rodean. Una convivencia adecuada da confianza

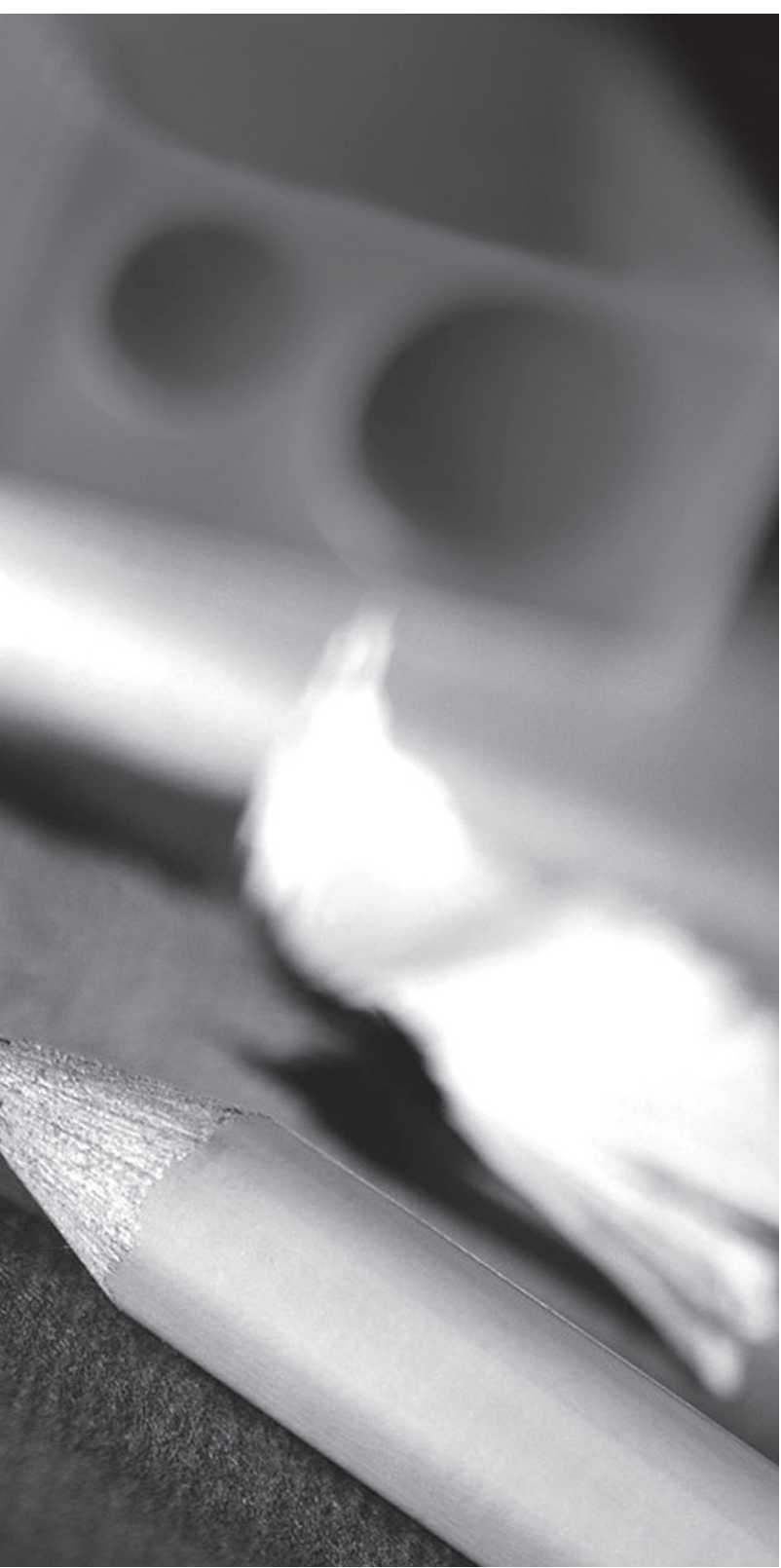

a la persona, puesto que esta es reconocida en su entorno social $y$, por tanto, puede desarrollar un sentido de pertenencia que potencia las acciones por emprender. Una relación en la enseñanza adecuada traducida en apoyo a los intereses, el estímulo oportuno, la comprensión de la identidad personal y el respeto, crean una mejor autoestima, lo que, a su vez, se traduce en un mejor rendimiento en el aprendizaje.

El toque relacional educativo pretendería hacer que los alumnos puedan expresar libremente susideas, pensamientos, anhelos, emociones, sentimientos, alegrías, identidades, etc. Una relación empática entre el profesor y el alumno puede ayudar a que se crezca con una personalidad proactiva en un ambiente en el que no prevalezca la discriminación, donde exista la afectividad, la autoestima, el autoconocimiento, la democracia y los valores en contraposición a la competencia desmedida, que favorece el valor por el éxito financiero.

El caso de Summerhill School es fuente inagotable de ideas sobre lo que una escuela democrática, libre y progresista puede aportar al desarrollo de la democracia. Summerhill fue fundada en 1921 por Alexander Sutherland Neill en Leisten, (Gran Bretaña). Actualmente es dirigida por su hija, Zoë Neill. En el mapa conceptual (anexo 2) se resumen los principios de la pedagogía de Summerhill, los cuales se basan en la libertad, la responsabilidad, la solidaridad y el respeto para los demás.

La escuela democrática y libertaria (caso de Summerhill) promueve

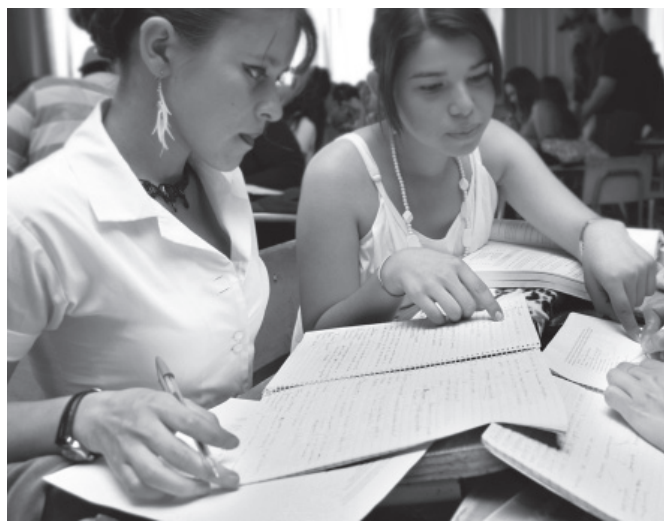

la democracia mediante prácticas democráticas visibles, es igualitaria; en ella se promueve que todos (los alumnos, profesores $y$ directores) tengan voz y voto en un autogobierno que funciona en consenso $y$ en el que el poder se reparte en lo administrativo, en un tribunal escolar; y en un poder legislativo, que crea normas $y$ acuerdos que todos cumplen porque los mismos nacen de la participación de todos los involucrados.

La escuela se basa en la libertad para que los alumnos puedan amar la vida, puedan decidir por ellos mismos qué hacer en la escuela, distinguiendo la diferencia que existe entre libertad y libertinaje, en donde se ejercita la responsabilidad y se practica el respeto a la dignidad y el libre desarrollo, en donde el aula es opcional. Summerhill es una escuela en donde el toque relacional se fortalece por medio del afecto, de la felicidad, la alegría; en donde la emoción es primaria, gobierna el corazón y hay relaciones amigables entre todos; se practica el desarrollo de la identidad personal, la dignidad humana y la persona.

La experiencia incluye una educación basada en el constructivismo, 
la incorporación de valores; se promueve la crítica, la discusión, la cual no sólo es intelectual, sino afectiva. El informe de inspección de Ofsted de noviembre del 2007, dice: "Summerhill provee una satisfactoria calidad de educación para sus alumnos. Los alumnos aprenden apropiadamente $\mathrm{y}$ hacen progresos satisfactorios en sus cursos acreditados...".

\section{ESTRATEGIA DE CAMBIO}

Pasar de una situación tradicional a una de vida democrática y de libertad implica una serie de proyectos articulados y que sean sinérgicos entre sí. Se pueden mencionar algunos. En primer lugar, hay que clarificar y consensuar qué tipo de democracia se quiere: participativa, representativa, pluralista, deliberativa, congregativa... En segundo lugar, hay que fortalecer en forma visible el ejercicio de la democracia, y si esta es deliberativa, en la cual se parte de ciudadanos libres e iguales, (Magendzo, 2007).

Hay que tener procesos en los cuales se promueva la argumentación, la reflexión para llegar a puntos de encuentro y acuerdos. Crear espacios relacionales para vivenciar los valores democráticos en un desarrollo cotidiano, no actos aislados para elegir en un gobierno cada cierto tiempo. La discusión y el diálogo tienen beneficios para las decisiones políticas: contar con información, enriquecer la racionalidad, tomar decisiones más participativas, cívicas, solidarias, etc.

Un buen proyecto, según el actor citado, se indica (es visible) porque lo público es político, la deliberación es cotidiana; se aprende para la argumentación y también para poder aceptar explicaciones.

Es informada y respeta los derechos humanos, valora la reciprocidad y se deja con tiempo suficiente para que las deliberaciones fluyan libremente. Hay canales para participar y se privilegia la participación deliberativa por sobre el poder corporativo o impositivo. En cuanto a lo curricular (Earls y Carlson, 1995) ordenan las capacidades para la deliberación: capacidad para comunicarse, convencer, argu-

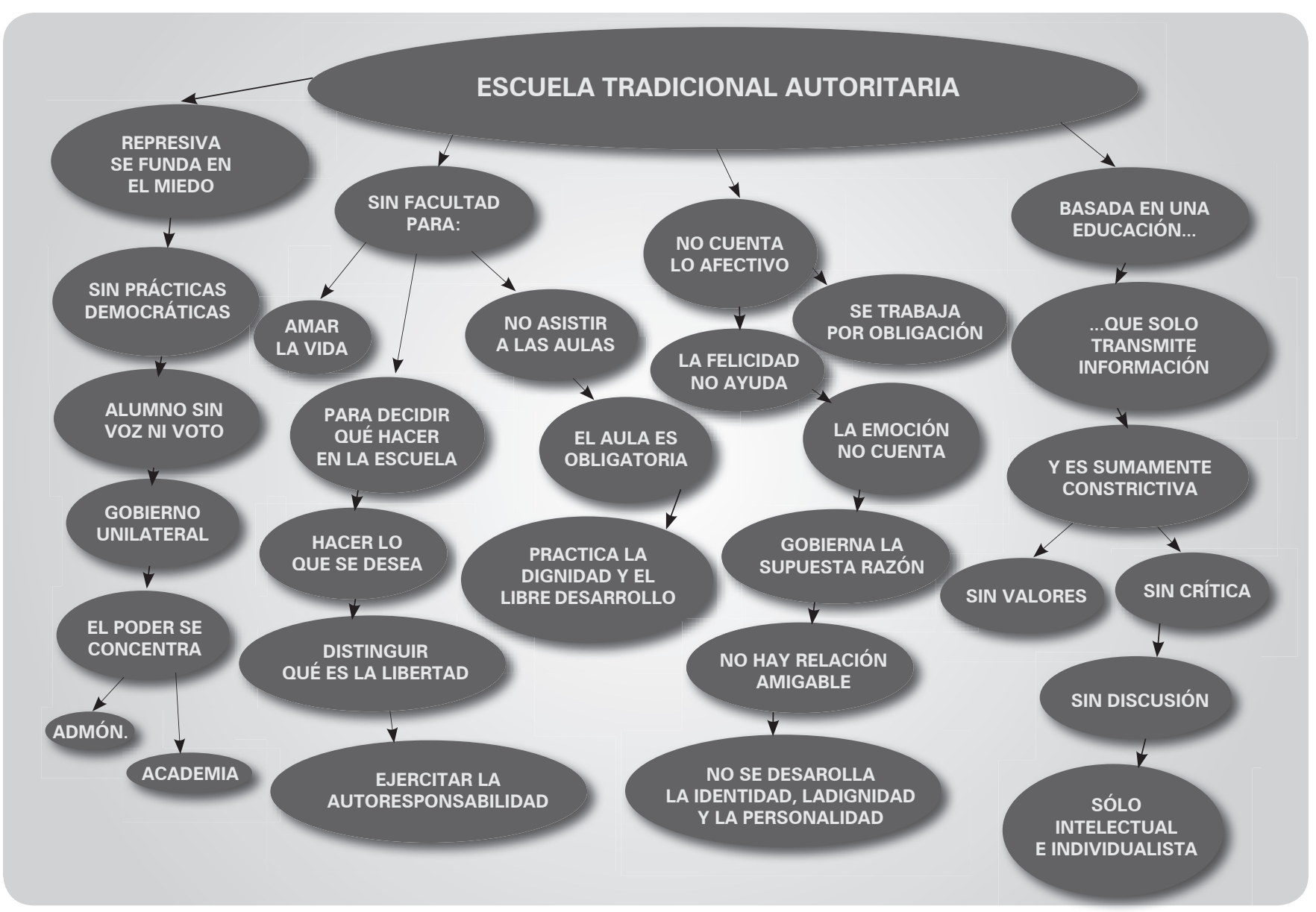




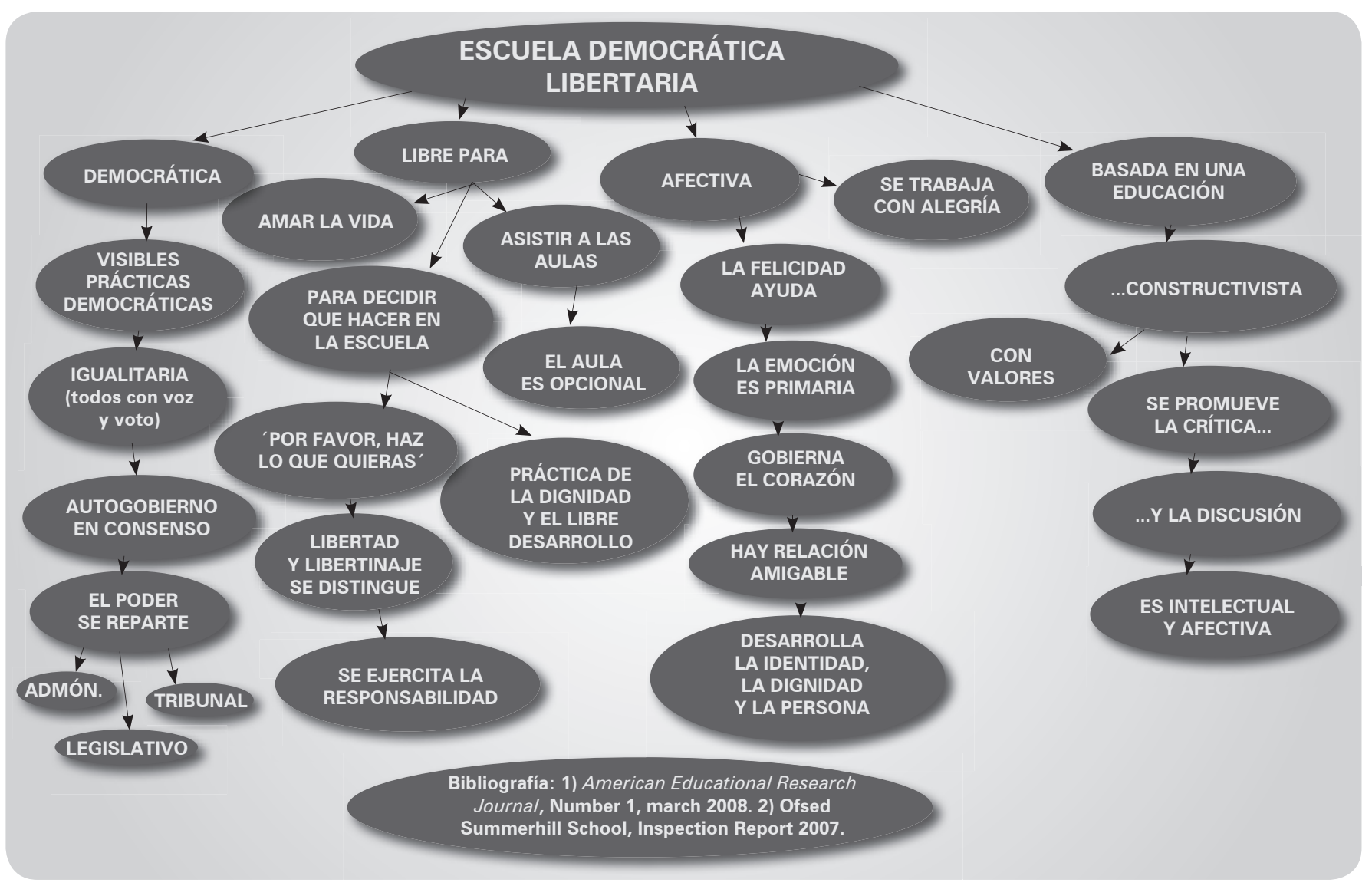

mentar; capacidad para analizar hechos, normas, sentimientos, para convenir, dudar, tomar decisiones, y, por último, la capacidad emocional para inspirar confianza, respeto, actuar y autorregularse.

La democracia debe fortalecerse aun y cuando sus resultados no sean satisfactorios. El proceso democrático tiene valores más allá de lo tangible; la búsqueda de la solidaridad y el bien común lo merecen. La escuela debe cambiar para formar ciudadanos libres y democráticos.

\section{BIBLIOGRAFÍA}

- American Educational Research Journal. Volumen 45. Number 1. March 2008.

- Ofsted*. Summerhill School. Independent School. Inspection report 6-7. November 2007.

- Korin Renck y Leonardo Landaverde. Educación y epistemología relacional.

- Complexus. Revista de Complejidad, Ciencia y Estética Sintesys. Chile.

- Olom, A. (202). La construcción del comportamiento pedagógico: nuevas perspectivas en teoría de la educación. Barcelona. Paidós.

- Coorporación Educacional de la Cámara Chilena de la construcción (2004). Programa de Desarrollo de la Autoestima.

- $\quad$ Milicie, N (2001). Creo en ti: la construcción de la autoestima en el contexto escolar.

Santiago de Chile. Lom ediciones.

- Abrahan Magendzo Kolstrein. "Formación de estudiantes deliberantes para una democracia deliberativa". REICE (Revista Electrónica Iberoamericana sobre calidad eficacia y cambio en educación) 2007. Volumen 5. №. 4.

Abad, Raúl (2003). Marketing relacional, futuro relacional. Editorial Espasa Calpe. Barcelona.

Navarro, Eduardo. ¿Qué es $C R M^{* *}$ ? Editorial Limusa, Madrid. 2002.

*Ofsted. Es la oficina que establece estándares para educación que se reporta directamente al parlamento Inglés.

** CRM: Customer Relationship

Management.

*** Imagine a school...

Where kids have freedom to be themselves... Where success is not defined by academic achievement but by the child`s own definition of success...

A. S. Neill's Summerhill :

http://www.summerhillschool.co.uk 